\title{
The effect of preliminary processing and different methods of cooking on the iodine content and selected antioxidative properties of carrot (Daucus carota L.) biofortified with (potassium) iodine
}

\author{
Joanna Kapusta-Duch ${ }^{1 *}$, Renata Bieżanowska-Kopećl, Sylwester Smoleñ ${ }^{2}$, \\ Mirostaw Pysz ${ }^{1}$, Aneta Kopećl, Ewa Piątkowska ${ }^{1}$, Roksana Rakoczy', \\ Aneta Koronowicz ${ }^{1}$, Lukasz Skoczylas ${ }^{3}$, Teresa Leszczyńska ${ }^{1}$ \\ ${ }^{1}$ Department of Human Nutrition \\ Faculty of Food Technology, University of Agriculture in Krakow, Poland \\ ${ }^{2}$ Unit of Plant Nutrition, Institute of Plant Biology and Biotechnology \\ Faculty of Biotechnology and Horticulture, University of Agriculture in Krakow, Poland \\ ${ }^{3}$ Department of Fruit and Vegetable and Mushroom Processing \\ Faculty of Food Technology, University of Agriculture in Krakow, Poland
}

\begin{abstract}
Carrot is a vegetable that contains many nutrients and has strong antioxidant activity as well as pro-health potential. The level of bioactive compounds is strongly connected with the production chain. The thermal treatment of food products induces several biological, physical and chemical changes. In this study, changes in the levels of iodine, total carotenoids, total polyphenols as well as the antioxidant activity of unpeeled and peeled controls and carrots biofortified with (potassium) iodine (KJ) during cultivation due to the cooking and steaming process were investigated. The use of thermal processes resulted in a lower concentration of iodine in the roots of the control as well as in carrots biofortified with (potassium) iodine. In addition, peeling carrots caused higher losses of this trace element in the control and the biofortified carrots cooked or steamed for various times. In this study, a significant growth of the total carotenoids in peeled carrots biofortified with (potassium) iodine and of the total polyphenols in unpeeled carrots biofortified with (potassium) iodine under the influence of the cooking and steaming processes was observed compared with raw peeled and unpeeled biofortified carrots, respectively. Antioxidant activity significantly increased in the unpeeled and peeled carrots biofortified with (potassium) iodine under all thermal treatments in comparison with the raw unpeeled and peeled biofortified carrots.
\end{abstract}

Key words: antioxidant activity, biofortification, carotenoids, carrot, iodine, phenolic compounds

\section{INTRODUCTION}

Currently, there is a growing demand for natural, safe and functional foods. Consumers are interested in foods that have a positive impact on health, but contain no chemical additives or preservatives. The definition of functional foods is still evolving, but functional ingredients are commonly defined as safe dietary substances that beneficially affect

\footnotetext{
*Corresponding author.

Tel.: +48 1266248 16; fax: +48 1266248 12;

e-mail: j.kapusta-duch@ur.krakow.pl (J. Kapusta-Duch).
} 
specific goals in the body beyond providing adequate nutrition (Kazeem and Davies 2016).

Numerous epidemiological studies indicate that a diet rich in plant products reduces the risk of developing chronic non-communicable diseases (Dos Reis et al. 2015).

Iodine is an essential micronutrient for humans. It is responsible, among others, for the activity of thyroid hormones (Patrick 2008). One-third of the global population has inadequate iodine intake based on urinary iodine (UI) concentrations and 260 million people suffer from iodine deficiencies (WHO/UNICEF 2007). In order to counteract iodine deficiency in the human population, its supplementation through iodizing table salt (e.g. sodium chloride) has been applied in numerous countries as an efficient way of introducing this trace element into the human diet (Winger et al. 2008). However, excessive consumption of salt has recently contributed to the increased occurrence of cardiovascular diseases (He and MacGregor 2009). For this reason, the WHO has developed the Global Strategy on Diet, Physical Activity and Health for the years 2008-2013, which includes, among others, a reduction in salt intake accompanied with searching for other methods of introducing iodine into the daily human diet. One of these ways can be iodine biofortification of plants through fertilization during cultivation (White and Broadley 2009).

The biofortification of vegetables with deficient nutrients, especially trace elements (e.g. iodine), may improve the nutritional status of various populations and may prevent malnutrition from a lack of iodine (WHO/UNICEF 2007).

Numerous epidemiological studies clearly indicate the importance of fruits and vegetables as the richest potential source of bioactive compounds in daily human diets (Pascual-Teresa et al. 2010). Carrot (Daucus carota L.) has been considered one of the vegetables whose consumption has increased over the past years due not only to the nutritional and health benefits this vegetable provides, but also to the introduction of new varieties (e.g. coloured carrots). An increase in the amount of vegetables and fruit in the average diet has been recommended. Carrot roots are a good source of bioactive compounds: carotenoids, especially $\beta$-carotene and lutein, dietary fibre (pectins) as well as polyphenolic compounds (Arscott and Tanumihardjo 2010). Therefore, carrot can be an important vegetable in preventive nutrition (Alasalvar et al. 2001). The level of particular bioactive compounds in carrot varies depending on many factors, i.e. climatic conditions, growing locations, agronomic and harvest factors (Grajek 2007, Gamboa-Santos et al. 2013).

There is a growing interest in the changes of concentration of bioactive nutrients and non-nutrient bioactive compounds as well as antioxidant activities in vegetables as affected by the application of various thermal processes (boiling, microwaving, steaming, grilling, frying and baking) (Turkmen et al. 2005, Grajek 2007). The thermal treatment of various food products induces several biological, physical and chemical changes in nutrients as well as non-nutrient compounds. During the processing of vegetables, the most commonly used technique is cooking. High temperatures during cooking can affect the basic chemical composition of as well as activity of bioactive compounds. Changes in bioactive compound content during cooking may be the effect of two contrary phenomena: thermal treatment causes the denaturation of enzymes that are involved in the degradation of nutrients and bioactive compounds as well as cooking resulting in a softening effect, which increases the extractability of bioactive compounds, resulting in a higher level in cooked products as compared to the raw material (Palermo et al. 2014). It is therefore reasonable to gain more knowledge about the fate and the final concentration of bioactive compounds before and after food processing to assess the availability of them within a diet.

The incorporation of iodine (in forms of iodides or iodates) directly into plants (especially vegetables) through fertilization has received very little research attention. In this study, the effect of cooking and steaming processes without the addition of salt on the concentration of iodine in carrots biofortified with this trace element was evaluated for the first time.

Since a large part of ingested vegetables have been thermally processed prior to consumption, it is necessary to investigate how thermal treatments affect the levels of analysed compounds. What is new in this study is that carrots biofortified with (potassium) iodine were chosen. The objective of this study was to assess the effects of cooking and steaming processes on the concentration of iodine, carotenoids, polyphenolic compounds and the antioxidant activity of unpeeled and peeled carrots subjected to iodine biofortification through fertilization. In general, this study was undertaken to broaden knowledge on the health-promoting properties of raw and conventionally boiled and steamed carrots, especially those biofortified with (potassium) iodine in terms of the above indicators. 


\section{MATERIAL AND METHODS}

\section{Plant material and treatments}

Carrot plants (Daucus carota L., 'Kazan' $\mathrm{F}_{1}$ ) were cultivated in 2012 in heavy soil (silt loam soil, $\mathrm{pH}$ 5.83) including the following treatments: 1 . control (without iodine application); 2. KI fertilization in a total dose of $5 \mathrm{~kg} \mathrm{I} \mathrm{ha}^{-1}\left(2.5 \mathrm{~kg} \mathrm{I} \mathrm{ha}^{-1}\right.$ pre-sowing and $2.5 \mathrm{~kg} \mathrm{I} \mathrm{ha}^{-1}$ as a top dressing - at canopy closure). Iodine was applied as pure salt KI (POCH Poland).

The carrots were cultivated in one row on $40 \mathrm{~cm}$ wide and $30 \mathrm{~cm}$ high ridges at a seeding rate of 37 seeds $\mathrm{m}^{-1}$ (approximately 550,000 seeds per hectare). The seeds were sown on 19 April 2012. The carrot roots were harvested on 29 September 2012. At harvest, approximately $25 \mathrm{~kg}$ samples of marketable yield of carrot storage roots were chosen from each of the four plots (replications) for cooking processes and laboratory analyses. The marketable yield consisted of the storage roots of cylindrical or close-to-cylindrical shape carrots with a head diameter of $\geq 3 \mathrm{~cm}$, undamaged by pests, not infected by fungi or bacteria, with no fractures and heads greened to a maximum of $0.5 \mathrm{~cm}$. The length of a storage root was $15 \mathrm{~cm}$ minimum.

\section{Cooking method}

The investigated material consisted of fresh carrots (biofortified or not biofortified with (potassium) iodine salt (KI)), peeled or not peeled (using a knife) before processing. The above-listed carrots were cooked in the laboratory, after cleaning and washing with tap water (in consumer conditions) and after separating the non-edible parts. Vegetables were put into boiling tap water (without salt) in a covered stainless steel pot (1:5, carrot/water) and cooked on a moderate flame. Cooking time, measured when the water started boiling again after adding the vegetables, was 20,30 , or $40 \mathrm{~min}$ (Fig. 1). Steaming treatments were carried out at $100^{\circ} \mathrm{C}$ under atmospheric pressure. The vegetables (200 g) were placed in a stainless steel steam cooker (Thermomix TM 31, Germany), which was covered with a lid and were steamed over boiling water at atmospheric pressure. The steaming times were as follows: 30 and $40 \mathrm{~min}$ (Fig. 1). Parts of the samples were cooled down, frozen in $-20^{\circ} \mathrm{C}$ and were kept until the freeze drying process.

\section{Measurement of the iodine concentration}

To measure iodine levels, the carrots were first lyophilized in a freeze dryer (Christ Alpha 1-4, Germany). The dried samples were ground in a variable speed rotor mill (Pulverisette 14
FRITSCH, Germany) using a $0.5 \mathrm{~mm}$ sieve. In the microwave system CEM MARS-5 Xpress (Germany), $0.5 \mathrm{~g}$ samples were mineralized in $10 \mathrm{~cm}^{3} 65 \% \mathrm{HNO}_{3}$ and $0.8 \mathrm{~cm}^{3} 70 \% \mathrm{HClO}_{4}$. After mineralization, the samples were transferred with double distilled water into test tubes to obtain a volume of $25 \mathrm{~cm}^{3}$. Iodine accumulation in carrot samples was assayed by the cold-vapour generator technique (Vtorushina et al. 2009) with the use of an ICP-OES spectrometer (Prodigy Teledyne Leeman Labs, USA). The procedure was validated by using spinach leaves (NCS ZC73013) with a certified concentration of iodine of $0.36 \mathrm{mg} \mathrm{I} \mathrm{kg}^{-1}$ d.w. \pm 0.12 as reference material. Iodine concentration in this material determined by the applied method was $0.39 \mathrm{mg} \mathrm{I} \mathrm{kg}^{-1}$ d.w. $\pm 0.08(\mathrm{n}=6)$ of iodine.

\section{The concentration of carotenoids}

The amount of total carotenoids was determined spectrophotometrically, according to the Polish Standard with modification (PN-90/A-75101/12) under dark conditions to protect carotenoids from light degradation. Samples were homogenised with an extraction solvent (acetone-hexane mixture, 4:6 $\mathrm{v} / \mathrm{v}$ ) and then the optical density of the supernatant at a wavelength of $450 \mathrm{~nm}$ was measured by a RayLeigh UV-1800 (China) spectrophotometer and compared with a standard curve (standard range of 0-30 milligrams).

The material ( $2 \mathrm{~g}$ of freshly processed carrots) was crushed using a homogenizer (CAT type X 120, USA) and then was transferred to a porcelain mortar. Thereafter, approximately $2 \mathrm{~g}$ of sand was used to extract the dye from the carrot using a mixture of hexane-acetone and then the extract was poured into a test cylinder. The procedure was repeated until the complete decolouration of samples. Then the extract volume of a cylinder measuring cup was read, shaken and allowed to stand in a dark place for 30 minutes. After this time the absorbance of the solution was measured. Results were calculated based on a standard curve prepared from $\beta$-carotene (trans- $\beta$-carotene, catalogue no. C-9750, "approximately 95\% UV synthetic, powder type I", Sigma-Aldrich, St. Luis, Missouri, USA).

\section{Methanolic extract preparation}

The fresh material was crushed using a homogenizer (CAT type X 120, USA) and then was used to prepare methanol extracts (5 $\mathrm{g}$ of raw vegetables in $80 \mathrm{~mL}$ of $70 \%$ methanol solution). In each case, fresh plant materials were extracted by shaking (Elpan, water bath shaker type 357, Poland) at 
room temperature for 2 hours, and the solution was centrifuged at 3,000 rpm (Centrifuge type MPW-340, Poland), filtered and then the extracts were stored at $-22^{\circ} \mathrm{C}$ until analysis (Pellegrini et al. 2003). Methanolic extracts were used for the measurement of polyphenolic compound content and the antioxidant activity of unprocessed and processed carrots biofortified with (potassium) iodine through fertilization.

\section{Total polyphenolic compound concentration}

The above-described methanolic extracts $(5 \mathrm{~g}$ of raw vegetables in $80 \mathrm{~mL}$ of $70 \%$ methanol solution) were used to establish the total polyphenolic compound content, using the Folin-Ciocalteau reagent (Sigma-Aldrich St. Luis, Missouri, USA). The method involved the colorimetric determination of coloured products that formed when phenolic compounds reacted with the FolinCiocalteau reagent (Poli-Swain and Hillis 1959). The content of total polyphenolic compounds in the carrot extracts was determined spectrometrically (at a wavelength of $760 \mathrm{~nm}$ using a RayLeigh UV-1800 spectrophotometer, China) according to the Folin-Ciocalteau procedure and calculated as chlorogenic acid equivalents (CGA) in terms of milligrams per $100 \mathrm{~g}$ of fresh weight, based on a standard curve (standard range of 0-40 milligrams).

\section{Antioxidant activity}

Identical methanolic extracts ( $5 \mathrm{~g}$ of raw vegetables in $80 \mathrm{~mL}$ of $70 \%$ methanol solution) were also used to determine (spectrometrically) the antioxidant activity by identifying the sample's ability to extinguish an $\mathrm{ABTS}^{++}\left(2,2^{\prime}\right.$-azinobis-(3ethylbenzothiazoline-6-sulfonic acid) free radical (Re et al. 1999). This in vitro assay involves the generation of a relatively stable free radical that loses colour after scavenging electrons from lipophilic and hydrophilic antioxidants in a sample. The colour change, monitored by the change in absorbance at $734 \mathrm{~nm}$ after a specified time and temperature $\left(6 \mathrm{~min}\right.$ at $\left.30^{\circ} \mathrm{C}\right)$ is proportional to the antioxidant concentration. $\mathrm{ABTS}^{\cdot+}$, potassium persulfate, and Trolox were purchased from Sigma-Aldrich (SigmaAldrich St. Luis, Missouri, USA). The absorbance was measured at a wavelength of $734 \mathrm{~nm}$ using a RayLeigh UV-1800 spectrophotometer (China). Values obtained for each sample were compared to the concentration - response curve of the standard Trolox solution (standard range of $0-10 \mu \mathrm{mol}$ ) and expressed as micromoles of Trolox equivalent per gram of fresh weight (TEAC).

\section{Statistical analysis}

The values presented in the tables were calculated based on a completely randomized design (CRD) in a factorial scheme of $6 \times 2 \times 2$ (6 types of thermal treatment $\times$ peeled or unpeeled $\times$ fortified with iodine or not).

For each sample, the chemical analyses were done in three replicates $(n=3)$ with the relative error not exceeding 5\%. The arithmetic mean was adopted as the final result. The standard deviations (SD) were also calculated for all mean values. All calculations were made by using the Statistica 9.1. package (StatSoft, Inc., Tulsa, Oklahoma USA). Three-way analyses of variance were applied. The significance of differences was estimated using the Duncan test at the critical significance level of $p \leq 0.05$. The correlation between the content of total polyphenols and the antioxidant activity at 0.05 level of confidence was also calculated.

\section{RESULTS AND DISCUSSION}

\section{The effect of biofortification of carrots in iodine}

Soil fertilization with potassium iodide effected a higher concentration of iodine in raw carrot roots (calculated per fresh and dry weight of roots - Figs $1 \mathrm{~A}$ and $\mathrm{B}$, respectively). The content of this trace element in unpeeled and peeled carrots was much higher when compared to respective roots from the control combination. We also found that the process of peeling did not affect the level of iodine noted in the control carrot roots. In biofortified carrots however, peel removal significantly decreased the iodine content when compared to the untreated roots.

The epidermis of carrot storage roots is the first barrier in the intake of nutrient compounds by the roots (Pinto and Ferreira 2015). It can also affect the transport of nutrient compounds to the stele, xylem and upper parts of the plants. Results obtained in this study clearly indicate that the removed parts of carrot roots (the cork and phellogen layer) contained a significant amount of iodine. Iodine accumulation in the epidermis of storage roots can be the effect of plant defence against the excessive intake of this trace element. Iodine is not an essential nutrient for plant growth (Kabata-Pendias 2011). The important finding of this study is that iodine content in storage roots biofortified by soil fertilization with $5 \mathrm{~kg}$ $\mathrm{I} \mathrm{ha}^{-1}$ without the epidermis was still substantial. In our opinion, the introduction of biofortified carrots to agricultural production could increase the concentration of iodine in average daily 


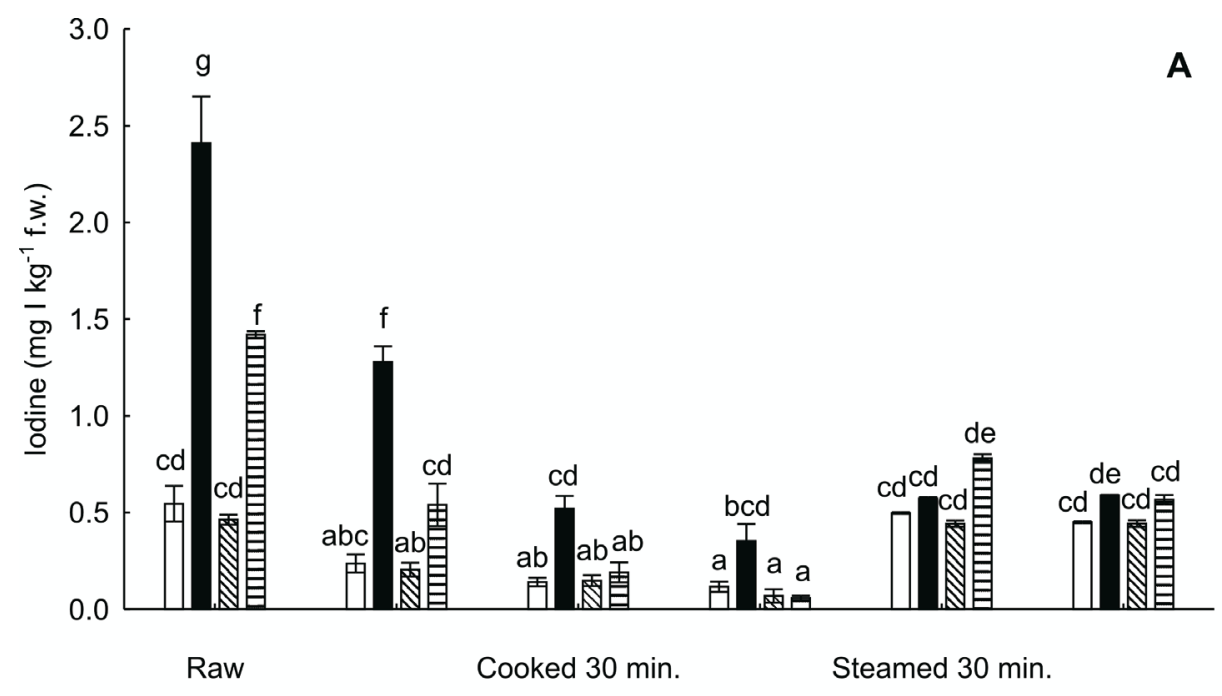

Cooked $20 \mathrm{~min}$ Cooked $40 \mathrm{~min}$ Steamed $40 \mathrm{~min}$.

Method of culinary preparation

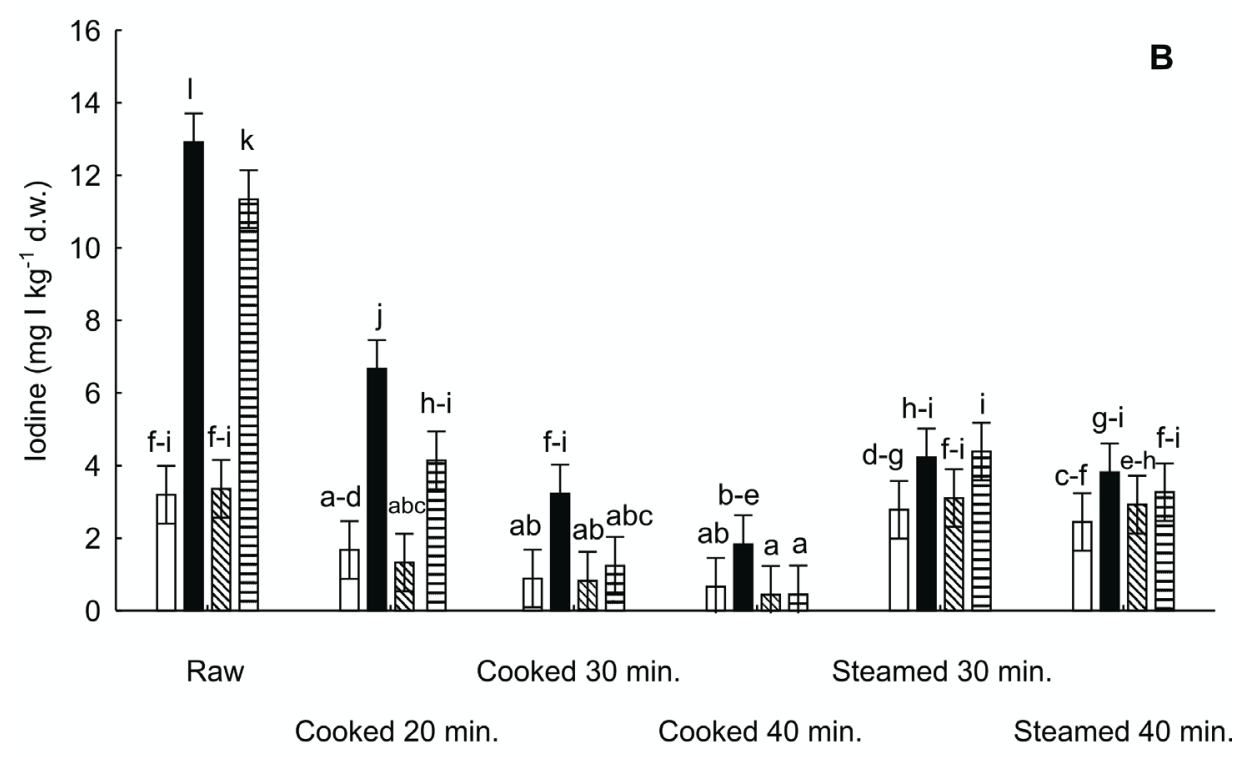

Method of culinary preparation

$\square$ Unpeeled control carrot, Unpeeled carrot biofortified with $\mathrm{KI}$

Peeled control carrot, Peeled carrot biofortified with KI

Figure 1. Content of iodine in carrot depending on biofortification, peeling and cooking method calculated per fresh (A) and dry weight (B) of storage roots. Means followed by the same letters are not significantly different at $p \leq 0.05$, $(\mathrm{n}=3)$; bars indicate standard deviation

diets. Recommended Nutrient Intake (RNI) or Recommended Daily Allowances (RDA) for iodine depend on age and gender. For children above 12 years old and adults, RNI/RDA is recommended at the level of $150 \mu \mathrm{g}$ I per day (WHO/UNICEF 2007). In Poland, the average consumption of one portion of carrots was assessed at the level of $100 \mathrm{~g}$ f.w. (Włodarek and Głąbska 2010). With one portion of fresh carrots it is possible to consume about $142 \mu \mathrm{g}$ I. This amount of carrots can meet the requirement for iodine intake at $80 \%$. It should also be mentioned that in previous studies published by Smoleń et al. (2011), soil fertilization with iodine in the form of $\mathrm{KI}$ and $\mathrm{KIO}_{3}$ in a dose of $2 \mathrm{~kg} \mathrm{I} \mathrm{ha}^{-1}$ (heavy soil, $\mathrm{pH}$ 6.80-7.10) was less effective with respect to carrot biofortification. In this study, the content of iodine in unpeeled carrot roots ranged between 7.4-17.6 $\mu \mathrm{g} 100 \mathrm{~g}^{-1}$ f.w. Iodine was applied simultaneously with various types of nitrogen fertilization. It has been demonstrated that the optimization of agrotechnical rules of iodine biofortification is an important factor 
affecting the efficiency of this process. What should be particularly taken into consideration is iodine dosage, its chemical form and its method of application as well as the introduction of additional mineral nutrients. The intake of iodine from soils is limited by intensive sorption processes and changes of iodine complexes in soil (Sheppard and Hawkins 1995, Ashworth et al. 2003, Yuita et al. 2005, Ashworth and Shaw 2006a, Ashworth and Shaw 2006b).

\section{The effect of thermal processes on iodine concentration in carrots}

In general, the content of iodine ranged from 0.44 (unpeeled control carrot cooked for $40 \mathrm{~min}$ ) to $12.36 \mathrm{mg} \mathrm{I} \mathrm{kg}^{-1}$ dry weight of vegetables (unpeeled raw carrots biofortified with (potassium) iodine). The content of iodine in raw carrots ranged from 3.19 to $12.91 \mathrm{mg} \mathrm{I} \mathrm{kg}^{-1}$ dry weight of carrots (Fig. 1). The highest concentration of this compound in raw vegetables was determined in unpeeled biofortified carrots compared with peeled carrots biofortified with (potassium) iodine (11.34), and the peeled and unpeeled control (3.19 and 3.36, respectively).

It was generally found that the use of thermal processes (cooking or steaming) lowered iodine concentration in the roots of both control and biofortified carrots (calculated per fresh and dry weight of roots - Figs $1 \mathrm{~A}$ and B, respectively). The final iodine content after cooking and steaming for all types of carrots ranged between 0.44 and $6.67 \mathrm{mg} \mathrm{I} \mathrm{kg}^{-1}$ dry weight of vegetables. What is more, peeling biofortified carrots contributed to additional losses of this trace element in the control and carrots biofortified with (potassium) iodine subjected to both thermal processing methods. Still, a higher content of iodine was measured in steamed carrots than in carrots cooked for 30 and 40 minutes. The range of iodine losses during 30 and 40 min of steaming was comparable to losses of it in unpeeled or peeled carrots. The peeling of carrots increased the loss of iodine in biofortified vegetables during the cooking process. Compared to carrots biofortified in iodine and cooked by steaming, the peeling of carrots had no effect on the loss of this element.

In the case of biofortified carrots, we found that increasing the time of cooking significantly decreased the content of iodine. It should be noted that biofortified peeled carrots cooked for 30 or 40 min had a lower concentration of iodine than raw control carrots.
The results obtained in this study showed that cooking processes caused the highest losses of iodine in both the control and biofortified unpeeled carrots and the peeled control and biofortified carrots.

In this study we found that carrot roots can cumulate iodine. Additionally, the content of iodine depends on the thermal processes that are used. Little information can be found in the literature describing the effect of various thermal processes on iodine content in vegetables. Kiferle et al. (2013) reported that the cooking process also caused losses of iodine in unpeeled or peeled tomato. Salau et al. (2010) reported that losses of iodine from plant food depend not only on the time of cooking but also on the form of the plant product after its processing (e.g. pulp, final meal). The range of iodine losses noted in products used in these studies was between 30 and $40 \%$. However, the authors did not present detailed information concerning the conditions of the cooking process. On the other hand, the study by Cerratini et al. (2014) evaluated the stability of iodine derived from biofortified potatoes in the preparation process of some Italian dishes. The results of these authors showed a good stability of iodine in cooking processes, also confirming the results of Comandini et al. (2013). In the paper by Cerratini et al. (2014), the authors suggested that the presence of potato skin during boiling might have represented a physical barrier that limited the leaching of this compound into water. In this study a similar trend was also observed (except for carrots steamed for $30 \mathrm{~min}$ ). It was also stated that changes of iodine content in various vegetables after cooking were lower compared to its oxidation in iodized salt. The production, transport and the addition of iodized salt to cooking dishes can contribute to a loss of iodine of up to $90 \%$ (Winger et al. 2008). It can also be noted that the iodine biofortification of vegetables can be introduced as a good source of this trace element in a daily diet since in many cases they can be consumed raw without any thermal processing.

\section{The effect of thermal processes on carotenoid concentration in carrots}

Carotenoids are susceptible to degradation by chemical and physical factors, including exposure to light, oxygen, elevated temperature and others. Therefore, depending on the conditions of thermal processes, such as time and temperature, these compounds can be more or less affected, resulting 
in a decrease or increase of their amounts (Murador et al. 2014).

The content of total carotenoids ranged from 16.68 (peeled control carrot steamed for $40 \mathrm{~min}$ )

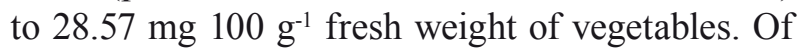
the raw carrots, the lowest mean content of total carotenoids was found in the peeled control (19.51), while the highest was in the unpeeled control carrot (28.57) and unpeeled carrot biofortified with (potassium) iodine $\left(22.52 \mu \mathrm{mol} \mathrm{g} \mathrm{g}^{-1}\right.$ dry weight) (Fig. 2).

The highest content of carotenoids was measured in unprocessed and unpeeled control carrots as compared to cooked or steamed unpeeled control carrots (from 18.43 to $22.68 \mathrm{mg}$ $100 \mathrm{~g}^{-1}$ fresh weight of vegetables) or peeled control carrots (16.68-18.23) and unpeeled or peeled carrots biofortified with (potassium) iodine (20.02-27.73) (Fig. 2). It was also found that unpeeled biofortified carrots cooked for $20 \mathrm{~min}$ had the highest level of carotenoids (27.73) compared to all unpeeled and peeled carrots thermally treated in varied times. The process of cooking carrots caused a generally significant $(p \leq 0.05)$ decrease in the total carotenoid content compared with raw unpeeled carrots. The concentration of carotenoids in peeled control carrots cooked in various times was generally similar. Peeled carrots biofortified with (potassium) iodine cooked for $40 \mathrm{~min}$ had the highest content of carotenoids (25.71) compared to other biofortified peeled carrots cooked for 20 (24.77) or $30 \mathrm{~min}$ (23.71) as well as unpeeled carrots biofortified with (potassium) iodine cooked and steamed for 30 and $40 \mathrm{~min}$. The process of steaming caused a significant $(p \leq 0.05)$ reduction in the content of carotenoids in the control or biofortified, unpeeled or peeled carrots compared with the unpeeled control carrots. In this study we observed a significant $(p \leq 0.05)$ growth of total carotenoids in peeled carrots biofortified with (potassium) iodine under the influence of the cooking and steaming processes compared with raw peeled biofortified carrots. The increase was directly proportional to the steaming time (30, $40 \mathrm{~min})$.

In the available literature, there is a lack of data concerning the effect of biofortification of carrots with iodine and its effect on the concentration of carotenoids. The results obtained in this study are inconclusive and do not correspond on the whole with results reported by Mazzeo et al. (2011). These authors have shown that the traditional cooking process in water and steaming resulted in a reduction of carotenoids. Pinhero-Sant'Ana et al.
(1998) compared the effect of the different methods of cooking carrots in industrial environments and reported that the highest losses of $\alpha$ - and $\beta$-carotene in steamed carrots were in the range of $44 \%$.

Some data obtained in this study correspond with previously published results concerning the effect of various thermal processes on the carotenoid content in vegetables. In some studies, it was reported that the thermal processes increased the concentration of carotenoids in vegetables. It was also reported that the quantity of the losses of these substances may have been influenced by both the various parameters of the processes used and the properties of the vegetables (Mayer-Miebach et al. 2005). Miglio et al. (2008) also measured a higher concentration of various carotenoids, apart from $\alpha$-carotene, in cooked carrots compared to raw carrots. These differences can be justified by the structural specificities of the carotenoids such as molecular shape, ease of crystal formation, storage of various locations in cells or further organization in multilayers or aggregates (Murador et al. 2014). Further research is needed to increase knowledge regarding the bioavailability of total carotenoids from vegetables, and to confirm the effects of various domestic cooking methods on the concentration and structure of these compounds. The content of carotenoids in vegetables depends on various factors, among which are: the climatic conditions, agrotechnical treatments, time of harvesting, and storage conditions (Arscott and Tanumihardjo 2010, Gamboa-Santos et al. 2013). Carotenoids are lipophilic and they are restricted to hydrophobic areas in cells, but these compounds can be associated with different proteins in complexes. Protein-carotenoid complexation has been shown to exert an inhibitory effect on carotenoid extractability (Schweiggert et al. 2014). In some cases (e.g. in this study), heat treatment may cause an increase in carotenoids through the release of carotenoids from the carotenoid-protein complexes and changes occurring in proportions of soluble to insoluble components of vegetables (Scott and Eldridge 2005). Thermal processes denature the proteins, softening the cell walls and releasing these compounds from these complexes, which can be a possible reason for the increase of carotenoid amounts in some cooked or steamed vegetables (Murador et al. 2014). The results obtained indicate that further studies are needed to explain changes in carotenoid contents during convectional cooking and steaming in not only biofortified carrots. As the results presented by other authors and those 


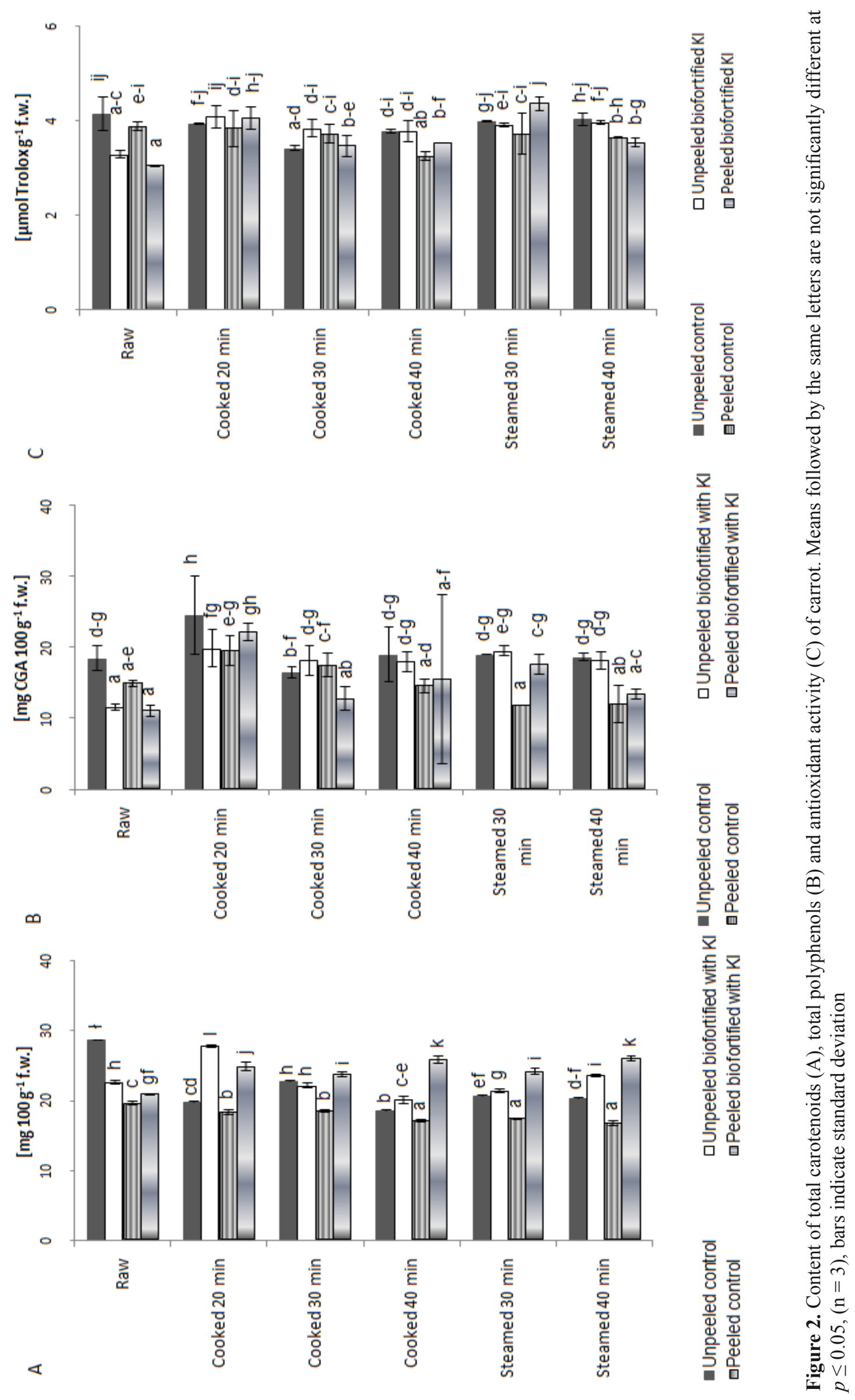


obtained in this work are not clear-cut, the research problem seems to be interesting.

\section{The effect of thermal processes on phenolic compound concentration in carrots}

The content of polyphenolic compounds in plant raw materials is affected by a number of factors, such as climatic conditions and agro-technical practices, the stage of maturity, the time of harvest, storage conditions, genetic factors, varietal diversity, and the extent of damage to the vegetable tissue (Ninfali and Bacchiocca 2003). In the case of polyphenolic compounds strongly differing in terms of structure and properties, no less important are the conditions of their extraction from the raw material (for example, both 50 and $70 \%$ methanol and 70 or $80 \%$ acetone as well as $70 \%$ acetone acidified with acetic acid, etc.), methods of analysis as well as different manners of calculation depending on the standard used (Grajek 2007). The content of polyphenolic compounds in raw carrots ranged from 10.98 to

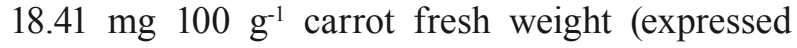
as the chlorogenic acid equivalents) (Fig. 2). The highest concentration of phenolic compounds in raw vegetables was determined in unpeeled control carrots compared with peeled control (14.86), unpeeled and peeled carrots biofortified with (potassium) iodine (11.49 and 10.98, respectively).

In general, the highest amounts of these compounds was found in unpeeled control carrots cooked for $20 \mathrm{~min}\left(24.49 \mathrm{mg} 100 \mathrm{~g}^{-1}\right.$ f.w.). Additionally, it was also found that cooking control or biofortified carrots for 20 min was the optimal time for maintaining a high content of phenolic compounds (19.43-24.49). In the case of steaming, the optimal time was $30 \mathrm{~min}$. The concentration of phenolic compounds in unpeeled control carrots cooked in various times (except carrots cooked for $20 \mathrm{~min}$ ) was generally similar. In this study we observed that the biofortification of carrots with iodine contributed to a significant decrease $(p \leq 0.05)$ in the polyphenolic content of raw roots. On the other hand, we also found that a significant $(p \leq 0.05)$ growth of total polyphenols in unpeeled carrots biofortified with (potassium) iodine under the influence of the cooking and steaming processes compared with raw unpeeled biofortified carrots.

The lowest level of phenolic compounds was determined in the peeled and unpeeled biofortified raw carrots and peeled control carrots steamed for $30 \mathrm{~min}$ (11.82). There were no significant differences $(p>0.05)$ in the concentration of polyphenolic compounds in unpeeled control or biofortified carrots between the time of cooking and steaming for 30 or for $40 \mathrm{~min}$. When steaming was applied (particularly for $40 \mathrm{~min}$ ), a higher content of phenolic compounds was noted for unpeeled (control carrots and carrots biofortified with (potassium) iodine -18.58 and 18.07, respectively).

The results obtained in our study concerning the effect of thermal processes on polyphenolic compound concentration are similar to data published by Sultana et al. (2008). These authors reported that the cooking process significantly increased the concentration of phenolic compounds in carrots from 0.33 to $0.79 \mathrm{mg} 100^{-1}$ d.w. On the other hand, Mazzeo et al. (2011) have shown that traditional cooking decreased the content of phenolic compounds in carrots. These authors also reported that the steaming process significantly increased the level of these compounds.

Data obtained in our study were not confirmed by data published by Miglio et al. (2008). These authors reported that the steaming process decreased the content of phenolic compounds. It has been also suggested that a longer time of thermal processes significantly decreases the content of phenolic compounds because some of them are changed from insoluble to the other soluble compounds soluble in water. Additionally, phenolic compounds found in peels are mainly removed during these processes (Gębczyński 2008). It has been also reported that peeling fruits or vegetables in order to remove their inedible parts or improve sensory profiles usually lowers the level of various bioactive compounds in edible products (Grajek 2007).

Polyphenols are compounds whose content changes upon the influence of treatment processes are not explicit. The content of phenolic compounds in such vegetables is influenced by storage time, temperature and the type of culinary and technological processing. A decrease in these compounds is usually caused by the leaching component, complexation with other compounds or oxidation (Grajek 2007). An increase in total polyphenol content might be due to the liberation of phenolics from intracellular proteins, changes in plant cell structure, matrix modifications, or the inactivation of polyphenol oxidase (Kao et al. 2014). An increase in polyphenol content is also associated with the reaction of plants to mechanical tissue damage, infection or other stress factors (Sikora et al. 2008). The roots of many plants exposed to heavy metals exude high levels of phenolics (Winkel-Shirley 2002). Iodine (as a non-nutrient compounds of plants) can be a stress 
factor for plants and can cause a higher synthesis of phenolic compounds in them. It is also well known that iodine in soil is connected with phenolic and polyphenolic compounds, which in their structure contain double bounds (Johanson 2000). Iodine in fulvic acids and humins is bounded in aromatic parts by covalent bonds (Schlegel et al. 2006). It can also be suggested that the storage roots of carrots could absorb low molecular weight compounds, i.e. iodine and fulvic acids or iodine and humins, from the soil and store them in peels (Grajek 2007). This can also explain the higher content of phenolic compounds in raw biofortified unpeeled carrots as compared to biofortified peeled carrots thermally treated for $40 \mathrm{~min}$ (cooked or steamed). The explanation of this suggestion is based on previous results. It was found that the addition of humic acids affected the concentration of iodine in spinach (Smolen and Ledwożyw-Smolen 2011). The higher synthesis of polyphenolic compounds was also determined in the hydroponic growth of salad biofortified with a relatively high level of iodine in the forms $\mathrm{I}^{-}$and IO $^{3-}$ (respectively: 20, 40, $80 \mu \mathrm{M} \mathrm{I}$ in both forms) (Blasco et al. 2008). Strzetelski et al. (2010) reported that the concentration of polyphenolic compounds in radish depends on the form and type of application (foliar and pre-sowing fertilization) of $\mathrm{KI}$ and $\mathrm{KIO}_{3}$. On the other hand, Smolen and Sady (2011) reported that the biofortification of spinach with relatively low doses of iodine $\left(1,2 \mathrm{mg} \mathrm{I} \mathrm{dm}^{-3}\right)$ did not affect the concentration of polyphenolic compounds in this plant. In other studies, the concentration of polyphenolic compounds in the roots of carrots grown in a pot cultivation experiment depended on the chemical form of iodine ( $\mathrm{I}^{-}$and $\mathrm{IO}^{3-}$ in a $1 \mathrm{mg}$ $\mathrm{I} \mathrm{dm}^{-3}$ soil dose) and nitrogen fertilizers (Smoleń et al. 2009). In this study, the concentration of polyphenolic compounds in carrots biofortified with iodine was lower than in the control carrots. Additionally, the concentration of these compounds in peeled carrots was lower than in unpeeled ones. It can be suggested that iodine was not the stress factor.

\section{The effect of thermal processes on the antioxidant activity of carrots}

When vegetables are submitted to cooking processes, variations appear in their antioxidant activity (Jiménez-Monreal et al. 2009). These variations depend on the conditions of thermal treatments, such as time, temperature, and the technique used, which clearly influence the levels of both the antioxidant activity of vegetables cooked using heating methods and the bioactive compounds present in vegetables, which will determine their antioxidant power (Murador et al. 2014).

In this study, significantly $(p \leq 0.05)$ higher antioxidant activity in the raw control carrots (4.14 $\mu$ mol Trolox $\mathrm{g}^{-1}$ f.w.) in comparison with the raw unpeeled and peeled biofortified with (potassium) iodine carrots (3.28 and 3.03, respectively) was determined (Fig. 1).

The thermal processes used in this study affected the antioxidant activity of carrots. It is worth mentioning that a reduced level of antioxidant activity due to iodine biofortification was observed only in raw carrots. Antioxidant activity significantly $(p \leq 0.05)$ increased in unpeeled and peeled carrots biofortified with (potassium) iodine under all thermal treatments in comparison with raw unpeeled and peeled biofortified carrots. Peeled control and peeled biofortified carrots cooked for 20 min had significantly higher $(p \leq 0.05)$ antioxidant activity compared to peeled control and biofortified carrots cooked for $40 \mathrm{~min}$. It was also found that $20 \mathrm{~min}$ of cooking control unpeeled or peeled or carrots biofortified with (potassium) iodine did not affect $(p>0.05)$ the antioxidant activity compared to the control raw unpeeled carrots. What is more, biofortified, peeled carrots cooked for $20 \mathrm{~min}$ had the strongest antioxidant activity compared to biofortified, peeled carrots cooked for 30 and cooked and steamed for $40 \mathrm{~min}$.

It can also be suggested that higher antioxidant activity was affected by an increased level of polyphenolic compounds and carotenoids after thermal processes. In this study, we have found a statistically significant $(p \leq 0.05)$ positive correlation (correlation coefficient was 0.702) between the higher content of total polyphenols and higher antioxidant activity in carrots.

In the study by Jiménez-Monreal et al. (2009), some possibilities are suggested for the increase in antioxidant activity of some vegetables during hydrothermal processes, such as the liberation of high amounts of antioxidant components due to the thermal destruction of cell walls and sub cellular compartments, the production of stronger antioxidants by thermal chemical reactions, suppression of the oxidation capacity of antioxidants by thermal inactivation of oxidative enzymes and the formation of novel substances, such as products of the Maillard reaction.

However, depending on the intensity and duration of the heat treatment, different compounds 
can be formed by the Maillard reaction. Products of this reaction with antioxidant properties and compounds with pro-oxidant properties are usually found during the early phases of the Maillard reaction (Nicoli et al. 1999, Manzocco et al. 2001, Faller and Fialho 2009).

The antioxidant activity of a vegetable is determined by factors such as its species, variety, tissue type, climate and environmental conditions during the vegetation period, plant maturation phase, storage temperature and duration, and thermal processing (Hazzani 1998). The total antioxidant potential of vegetable extracts also depends on the type and polarity of extraction solvent, isolation methods, purity of active substances, methodology and the substrates used (Meyer et al. 1998). It has been reported that various thermal processes and their duration time decreased the antioxidant activity in different fruits and vegetables (Grajek 2007, Jiménez-Monreal et al. 2009). Gębczyński (2008) reported that the cooking process of vegetables decreased the antioxidant activity of various vegetables from 5 to $53 \%$. Agostini et al. (2004) found that cooking onions decreased antioxidant activity within the range of $35 \%$. These authors suggested that this is mainly the effect of the losses of flavonoids during the cooking process. The study by Jiménez-Monreal et al. (2009) showed that the cooking process decreased the antioxidant activity of cooked carrots compared to control ones. According to Volden et al. (2009), a reduction in antioxidant activity during cooking was strongly affected by the cooking method and length of the process.

The water environment favours the rapid transfer of heat to the whole volume of the product. As a result, contact with heat is extended and the whole vegetable mass is heated uniformly. In such conditions antioxidants are oxidized. This causes the formation of complexes between antioxidants and other vegetable constituents. Additionally, enzymatic modifications occur as well as the oxidation of antioxidants or their extraction to a solution and conversion of their active form into a prooxidant. All of these reactions lead to losses in antioxidants in vegetables, thereby reducing their antioxidant potential activity.

Some studies have also reported that antioxidant activity was increased in carrots treated with various thermal processes. Sultana et al. (2008) reported that antioxidant activity was significantly increased in cooked carrots compared to raw ones. Miglio et al. (2008) also reported that conventional cooking and steaming increased the antioxidant activity of carrots. Mayer-Miebach et al. (2005) found that the thermal process increased the antioxidant activity of carrots (temp. $130^{\circ} \mathrm{C} ; 20 \mathrm{~min}$ ). Higher antioxidant activity of various vegetables was also reported by Turkmen et al. (2005). The main reason for this change of antioxidant activity was explained by a higher content of naturally occurring antioxidants as well as an increased biosynthesis of antioxidant compounds (Grajek 2007). Polyphenols in plants can occur in the form of glycosides as well as free aglycones. Thermal processes may affect the antioxidant activity. It is possible that during cooking the glycoside form of polyphenols can be changed to a more active aglycone form. Additionally, increasing or decreasing the polyphenol content in cooked vegetables depends on the content of free or bind polyphenolic compounds in the product before thermal processes (Dewanto et al. 2002).

\section{CONCLUSIONS}

1. The current study clearly shows that nutrient and health-promoting compounds in carrots are significantly affected by traditional cooking and steaming.

2. Raw biofortified carrots can be a good source of iodine, albeit the bioavailability of this trace element should be measured in in vivo studies.

3. In this study we observed a significant growth of the total carotenoids in peeled carrots biofortified with (potassium) iodine under the influence of the cooking and steaming processes compared with raw peeled biofortified carrots.

4. On the other hand, we also found a significant growth of the total polyphenols in unpeeled carrots biofortified with (potassium) iodine under the influence of the cooking and steaming processes compared with raw unpeeled biofortified carrots.

5. Antioxidant activity was significantly increased in unpeeled and peeled carrots biofortified with (potassium) iodine under all thermal treatments in comparison with raw unpeeled and peeled biofortified carrots.

\section{FUNDING}

This work was financed by the Polish National Science Centre - grant no. DEC-2011/03/D/ NZ9/05560 "I and Se biofortification of selected vegetables, including the influence of these microelements on yield quality as well as evaluation 
of iodine absorption and selected biochemical parameters in rats fed with vegetables biofortified with iodine" planned for 2012-2015.

The authors are grateful to Mariusz Doniec for his assistance in the implementation of the field experiment with the cultivation of carrots.

\section{AUTHOR CONTRIBUTIONS}

All authors contributed extensively to the work presented in this paper. J.K-D., R.B-K., S.S., M.P., A.K., E.P., R.R., A.K., Ł.S. - conceived and designed the study, participated in data collection and analyses and drafted the manuscript.

\section{CONFLICT OF INTEREST}

Authors declare no conflict of interest.

\section{REFERENCES}

Agostini L.R., Jimenez M.J.M., Ramon A.N., Gomez A.A., 2004. Determination of the antioxidant capacity of flavonoids in fruits and fresh and thermally treated vegetables. Arch. Latinoam. Nutr. 54: 89-92.

Alasalvar C., Grigor J.M., Zhang D.L., Quantick P.C., Shahidi F., 2001. Comparison of volatiles, phenolics, sugars, antioxidant vitamins, and sensory quality of different colored carrot varieties. J. Agr. Food Chem. 49(3): 1410-1416.

Arscott S.A., Tanuminardjo S.A., 2010. Carrots of many colors provide basic nutrition and bioavailable phytochemicals acting as a functional food. Compr. Rev. Food Sci. Food Saf. 9: 223-239.

Ashworth D.J., Shaw G., 2006a. A comparison of the soil migration and plant uptake of radioactive chlorine and iodine from contaminated groundwater. J. Environ. Radioact. 89: 61-80.

Ashworth D.J., Shaw G., 2006b. Effects of moisture content and redox potential on in situ Kd values for radioiodine in soil. Sci. Total Environ. 359: 244-254.

Ashworth D.J., Shaw G., Butler A.P., Ciciani L., 2003. Soil transport and plant uptake of radio-iodine from near-surface groundwater. J. Environ. Radioact. 70: 99-114

Blasco B., Rios J.J., Cervilla L.M., SÁnchez-Rodrigez E., RuIz J.M., ROMERo L., 2008. Iodine biofortification and antioxidant capacity of lettuce: potential benefits for cultivation and human health. Ann Appl. Biol. 152: 289-299.

Cerretani L., Comandini P., Fumanelli D., Scazzina F., Chiavaro E., 2014. Evaluation of iodine content and stability in recipes prepared with biofortified potatoes. Int. J. Food Sci. Nutr. 65(7): 797-802.

Comandini P., Cerretani L., Rinaldi M., Cichelli A., Chiavaro E., 2013. Stability of iodine during cooking: investigation on biofortified and not fortified vegetables. Int. J. Food Sci. Nutr. 64(7): 857-861.

Dewanto V., Wu X., Adom K.K., Liu R.H., 2002. Thermal processing enhances the nutritional value of tomatoes by increasing total antioxidant activity. J. Agric. Food Chem. 50(10): 3010-3014.

Dos Reis L.C., de Oliveira V.R., Hagen M.E., Jabloński A., Flôres S.H., De Oliveira Rios A., 2015. Effect of cooking on the concentration of bioactive compounds in broccoli (Brassica oleracea var. Avenger) and cauliflower (Brassica oleracea var. Alphina $\mathrm{F}_{1}$ ) grown in an organic system. Food Chem. 172: 770777.

FALler A.L.K., Fialho E., 2009. The antioxidant capacity and polyphenol content of organic and conventional retail vegetables after domestic cooking. Food Res. Inter. 42: 210-215.

Gamboa-Santos J., Soria A.C., Pérez-Mateos M., Carrasco J.A., Montilla A., Villamiel M., 2013. Vitamin $\mathrm{C}$ content and sensorial properties of dehydrated carrots blanched conventionally or by ultrasound. Food Chem. 136(2): 782-788.

GĘBCZYŃSKi P., 2008. Changes in the content of antioxidant compounds in frozen vegetables depending on the pretreatment conditions of storage and method of preparation for consumption. Scientific Papers of the Krakow Academy of Agricultural.

GrajeK W., 2007. Antioxidants in Food. Health Aspects, Technological, and Molecular Analysis. WNT, Warszawa, Poland.

HAzZANi I., 1998. Influence of locality and way of cultivation on the nitrate and glycoalkaloid content in potato tubers. Rost. Vyroba. 45(11): 495-501.

He F.J., Macgregor G.A., 2009. A comprehensive review on salt and health and current experience of worldwide salt reduction programmes. J. Hum. Hypertens. 23: 363-384.

Jiménez-Monreal A.M., García-Diz L., Martínez-Tomé M., Mariscal M., Murcia M.A., 2009. Influence of cooking methods on antioxidant activity of vegetables. J. Food Sci. 74(3): 97-103.

Johanson K.J., 2000. Iodine in soil. Technical Report TR-00-21. Svensk Kärnbränslehantering AB. http://193.235.25.3/upload/publications/pdf/TR-0021.pdf - version 22-01-2015.

Kabata-Pendias A., 2011. Trace Elements in Soil and Plants. CRC Press: Taylor and Francis Group, Boca Raton, FL, USA.

Kao F.J., Chiu Y.S., Chiang W.D., 2014. Effect of water cooking on antioxidant capacity of carotenoid-rich vegetables in Taiwan. J. Food Drug Anal. 22(2): 202209.

Kazeem M.I., Davies T.C., 2016. Anti-diabetic functional foods as sources of insulin secreting, insulin sensitizing and insulin mimetic agents. J. Funct. Foods 18: 122-138. 
Kiferle C., Gonzali S., Holwerda H.T., Real Ibaceta R., Perata P., 2013. Tomato fruits: a good target for iodine biofortification. Front. Plant Sci. 4: 205.

Manzocco L., Calligaris S., Masrrocola D., Nicoli K.C., Lerici C.R., 2001. Review on non-enzymatic browning and antioxidant capacity in processed foods. Trends Food Sci. Technol. 11: 340-346.

Mayer-Miebach E., Behsnilian D., Regier M., Schucgmann H.P., 2005. Thermal processing of carrots: Lycopene stability and isomerisation with regard to antioxidant potential. Food Res. Int. 38: 1103-1108.

Mazzeo T., N'dri D., Chiavaro E., Visconti A., Fogliano V., Pellegrini N., 2011. Effect of two cooking procedures on phytochemical compounds, total antioxidant capacity and colour of selected frozen vegetables. Food Chem. 128(3): 627-633.

Meyer A., Hainonen M., Frenkell E., 1998. Antioxidant interactions of catechin, cyaniding, cafeic acid on human LDL oxidation. Food Chem. 61: 71-75.

Miglio C., Chiavaro E., Visconti A., Fogliano V., Pellegrini N., 2008. Effects of different cooking methods on nutritional and physicochemical characteristics of selected vegetables. J. Agr. Food Chem. 56(1): 139-147.

Murador D.C., da Cunha D.T., de Rosso V.V., 2014. Effects of cooking techniques on vegetable pigments: A meta-analytic approach to carotenoid and anthocyanin levels. Food Res. Int. 65: 177-183.

Nicoli M.C., Anese M., Parpinel M., 1999. Influence of processing on the antioxidant properties of fruit and vegetables. Trends Food Sci. Technol. 22: 94-100.

Ninfali P., Bacchiocca M., 2003. Polyphenols and antioxidant capacity of vegetables under fresh and frozen conditions. J. Agric. Food Chem. 51: 22222226.

Palermo M., Pellegrini N., Fogliano V., 2014. The effect of cooking on the phytochemical content of vegetables. J. Sci. Food Agric. 94: 1057-1070.

Pascual-Teresa S., Moreno D.A., Garcia-Viguera C., 2010. Flavanols and anthocyanins in cardiovascular health: a review of current evidence. Int. J. Mol. Sci. 11: 1679-703.

PAtrick L., 2008. Iodine: deficiency and therapeutic considerations. Altern. Med. Rev. 13(2): 116-127.

Pellegrini N., Del Rio D., Colombi B., Bianchi M., Brighenti F., 2003. Application of the 2'2azobis (3-ethylenebenzothiazoline-6-sulfonic acid) radical cation assay to flow injection system for the avaluation of antioxidant activity of some pure compounds and bevereges. J. Agric. Food Chem. 51: 164-260.

Pinheiro-Sant'ana H.M., Stringheta P.C., Brandao S.C.C., Paez H.H., de Queiroz V.M.V., 1998. Evaluation of total carotenoids, alpha- and betacarotene in carrots (Daucus carota) during home processing. Ciênc. Tecnol. Aliment. 18: 39-44.
Pinto E., Ferreira I.M., 2015. Cation transporters/ channels in plants: Tools for nutrientbiofortification. J. Plant Physiol. 179: 64-82.

Poli-Swain T., Hillis W.E., 1959. The phenolic constituents of Prunus domesticus (L.). The quantity of analisys of phenolic constituents. J. Sci. Food Agric. 10: 63-68.

POLISH STANDARD, 1990 PN-90/A-75101/12. Polish Committee for Standardization. Food products Determination of total carotenoids and $\beta$-carotene.

Re R., Pellegrini N., Proteggente A., Pannala A., Yang M., Rice-Evans C., 1999. Antioxidant activity applying an improved ABTS radical cation decolorization assay. Free Radic. Biol. Med. 26: 1231-1237.

Salau B.A., Ajani E.O., Odufuwa K.T., Adegbesan B.O., Soladoye M.O., 2010. Effect of processing on iodine content of some selected plants food. Afr. J. Biotechnol. 9(8): 1200-1204.

Schlegel M.L., Reiller P., Mercier-Bion F., Barré N., Moulin V., 2006. Molecular environment of iodine in naturally iodinated humic substances: Insight from X-ray absorption spectroscopy. Geochim. Cosmochim. Acta 70: 5536-5551.

Scott E C., Eldridge L.A., 2005. Comparison of carotenoid content in fresh, frozen and canned corn. J. Food Comp. Anal. 18: 551-559.

Schweiggert R.M., Kopec R.E., Villalobos-Gutierrez M.G., Högel J., Quesada, S., Esquivel P., Schwartz S.J., CARle R., 2014. Carotenoids are more bioavailable from papaya than from tomato and carrot in humans: a randomised cross-over study. $\mathrm{Br}$. J. Nutr. 111(03): 490-498.

SHEPPARD M.I., HAwKins J.L., 1995. Iodine and microbial interactions in an organic soil. J. Environ. Radioact. 29(2): 91-109.

Sikora E., Cieślik E., Leszczyńska T., FilipiakFlorkiewicz A., Pisulewski P.M., 2008. The antioxidant activity of selected cruciferous vegetables subjected to aquathermal processing. Food Chem. 107: 55-59.

Smolé́ S., Ledwożyw-Smoleń I., 2011. The effect of humic acid concentrate on the effectiveness of iodine biofortification and biological quality of spinach plants. Environ. Prod. Nat. Resour. 48: 49-58.

Smolé́ S., Rożek S., Strzetelski P., Ledwożyw I., 2011. Preliminary evaluation of the influence of soil fertilization and foliar nutrition with iodine on the effectiveness of iodine biofortification and mineral composition of carrot. J. Elem. 16(1): 103-114.

Smoleń S., SAdy W., 2011. Influence of iodine fertilization and soil application of sucrose on the effectiveness of iodine biofortification, yield, nitrogen metabolism and biological quality of spinach. Acta Sci. Pol., Hortorum Cultus 10(4): 51-63.

Smoleń S., Sady W., Strzetelski P., Rożek S., LEDWOŻYW I., 2009. The effect of iodine and nitrogen fertilization on quantity and quality of carrot yield 
well as on biological quality of carrot. Environ. Prod. Nat. Resour. 40: 286-292.

Strzetelski P., Smoleń S., Rożek S., Sady W., 2010. The effect of differentiated fertilization and foliar application of iodine on yielding and antioxidant properties in radish (Raphanus sativus L.) plants. Ecol. Chem. Eng. A. 17(9): 1189-1195.

Sultana B., Anwar F., Iqbal S., 2008. Effect of different cooking methods on the antioxidant activity of some vegetables from Pakistan. Int. J. Food Sci. Technol. 43: 560-567.

Turkmen N., Sari F., Velioglu S., 2005. The effect of cooking methods on total phenolics and antioxidant activity of selected green vegetables. Food Chem. 93: 713-718.

Volden J., Bengtsson B.G., Wicklund T., 2009. Glucosinolates, L-ascorbic acid, total phenols, anthocyanins, antioxidant capacities and colour in cauliflower (Brassica oleracea L. ssp. botrytis); effect of long-term freezer storage. Food Chem. 112: 967-976.

Vtorushina E.A., Saprykin A.I., Knapp G., 2009. Use of oxidation and reduction vapor generation for lowering the detection limits of iodine in biological samples by inductively coupled plasma atomic emission spectrometry. J. Anal. Chem. 64(2): 129135.
White P.J., Broadley M.R., 2009. Biofortification of crops with seven mineral elements often lacking in human diets - iron, zinc, copper, calcium, magnesium, selenium and iodine. New Phytol. 182(1): 49-84.

WHO/UNICEF, 2007. Iodine deficiency in Europe: a continuing public health problem. Geneva ISBN 9789241593960.

Winger R.J., König J., House D.A., 2008. Technological issues associated with iodine fortification of foods. Trends Food Sci. Tech. 19: 94-101.

Winkel-Shirley B., 2002. Biosynthesis of flavonoids and effects of stress. Curr. Opin. Plant Biol. 5: 218.

WŁodarek D., GŁąBSKa D., 2010. Vegetables and fruits consumption by individuals with diabetes mellitus type 2. Practical Diabet. 11(6): 221-229.

Yuita K., Kinou N., Yabusaki S., Takahashi Y., Saitoh T., Tsumura A., Ichinashi H., 2005. Behavior of iodine in a forest plot, an upland field and a paddy field in the upland area of Tsukuba, Japan. Iodine concentration in precipitation, irrigation water, ponding water and soil water to a depth of $2.5 \mathrm{~m}$. J. Plant Nutr. Soil Sci. 51: 1011-1021.

Received January 12, 2016; accepted November 18, 2016 